\title{
Um museu para o Teatro ${ }^{1}$
}

\author{
Béatrice PICON-VALLIN ${ }^{2}$ \\ Centre National de la Recherche Scientifique (CNRS)/ARIAS
}

É profundamente lamentável que tantos esplêndidos cenários, tantos figurinos charmosos, tantos cortejos magnificos desapareçam sem deixar rastro. Todo esse luxo, todo esse encantamento, toda essa arte dispersa e perdida, todas as pródigas riquezas que devem, depois de passada a moda, envelhecer para sempre na poeira dos depósitos, inspiram um sentimento de saudade no mais indiferente dos espectadores. (Théophile Gautier - Lembranças do teatro, 1883,

Um número dos Cahiers de la Comédie-Française - o trigésimo - intitulado "Arquivar o Teatro" começava com um artigo que eu tinha escrito com Jean-Loup Rivière: "O ensinamento dos restos". Constatando a ausência na França de um grande museu de teatro, mesmo que a preocupação com o arquivamento esteja presente em diversas instituições (Departamento das Artes do Espetáculo da BNF, IMEC, Ópera de Paris, Comédie-Française, Maison Jean Vilar d'Avignon, CNT, Sociedade de História do Teatro), analisávamos as consequências de tal ausência. A visita à belíssima exposição consagrada à obra de André Acquart, cenografada pelo próprio artista, para o Departamento das Artes do Espetáculo da BNF, na cripta Richelieu, e a possibilidade que ela oferecia de percorrer ativamente 50 anos de teatro através das maquetes restauradas, das máscaras, dos figurinos, objetos, plantas e desenhos do artista, me revelaram a atualidade dessa constatação e o questionamento decorrente. A visita à exposição sobre "o cinema expressionista alemão", soberbamente montada no novo espaço da Cinemateca instalada em Bercy, depois, um andar abaixo, uma visita ao Museu do cinema, me fizeram reavivar. Por que então na França os amadores e os profissionais do teatro e das artes do espetáculo vivos não têm a possibilidade de se confrontar diretamente, passeando por salas que seriam dedicadas a isso, e examinando à vontade, as grandes linhas e os detalhes da história de "sua" arte?

Tudo se passa, como escrevemos com J.L. Rivière, como se o teatro fosse a única arte que pode dispensar o relacionamento com sua história. Claro, existem fundos muito ricos nas grandes instituições, mas esses lugares funcionam como bibliotecas: onde é preciso agendar consulta, saber o que se quer ver para pedir livros raros ou materiais. Essa

\footnotetext{
1 Traduzido do francês por Elizabeth R. Azevedo (Universidade de São Paulo - USP).

2 Béatrice Picon-Vallin é diretora de pesquisa do ARIAS (Ateliê de Pesquisas sobre a intermidialidade e as Artes do Espetáculo), que pertence ao CNRS, o prestigioso centro francês de pesquisa científica. Especialista de Teatro Russo e de História e Teoria da encenação, dirige a coleção Mettre en Scène da editora francesa Actes Sud - Papiers.
} 
prática diz respeito muito mais à pesquisa especializada. Ela é necessária; mas não seria possível imaginar que essas imagens, esses textos, essas maquetes fossem vistos em conjunto, expostos ao olhar atento daqueles que abrem as portas do museu onde estariam expostos os documentos e as obras mais significativas do patrimônio teatral francês? Imediatamente, dir-se-ia que essa situação deve-se ao status efêmero, perecível, da obra teatral, cada noite recriada e toda noite evanescendo nas lembranças de cada espectador. $\mathrm{O}$ espetáculo, a obra teatral, não permanece tangível uma vez as representações terminadas, mas, ao contrário de outras obras de arte, desaparece. Mesmo se, numa configuração ideal, conservássemos tudo de um espetáculo, sobrariam apenas os objetos que concernem a totalidade desse espetáculo... - rascunhos, desenhos, maquetes, figurinos, acessórios, músicas, máscaras... - ou traços - quadros, mapa da plateia, caricaturas, fotos, gravações de áudio ou vídeo, etc.

Estaríamos sublinhando, portanto, o caráter específico do teatro, sua instantaneidade, ao abrir mão de um museu. $\mathrm{O}$ vaz̧io seria o monumento dedicado ao efêmero. Por que então há museus de teatro em outros países, onde as criações cênicas mantêm ligações autênticas com a história das artes do espetáculo ${ }^{3}$ ? E por que se pode expor no Museu do cinema um vestido usado por Asta Nielsen na sua filmagem, e ninguém liga que não se possa ver um de Sarah Bernhardt? Objetar-se-á que um museu do traje foi recentemente aberto em 2006 em Moulins-sur-Allier, e que, na sua inauguração, ele recebesse o nome de Centro Nacional do Traje de Cena e da Cenografia ${ }^{4}$. Mas um Museu de Teatro é diferente, ele deve se interessar por todo tipo de restos, pois é a confrontação com esses diferentes objetos que suscita a evocação, ou o processo de compreensão, talvez de rememoração. Evidentemente, a amplitude da tarefa é impressionante, pois se refere a objetos dos mais variados: livros, manuscritos, cadernos de direção, correspondências, notas de direção, registros de contas, plantas, maquetes, croquis de figurinos e cenários, croquis, quadros, gravuras, esculturas, caricaturas, retratos, elementos de cenografia, cortinas, figurinos, acessórios, máscaras, partituras de música, de luz, sistemas de iluminação, materiais sonoros, fotografias, discos, filmes, cartazes, programas, convites, ingressos, jornais, revistas etc..

Os fragmentos e vestígios sustentam a obra teatral, eles permanecem como testemunhas, e são às vezes obras de artes em si, mas eles fazem sentido na sua interrelação. O conhecimento concreto dos materiais históricos, sua visibilidade, permitem uma

${ }^{3}$ Comédie-Française. O dossiê em Les cahiers de la Comédie-Française, n³0, 1999.

${ }^{4}$ Chama-se agora CNCS (Centro Nacional do Costume de Cena) e possui: 8500 figurinos de teatro, de ópera e de balé bem como cerca de trinta telas de cenário. São depósitos da Comédie-Française, da BNF e da Ópera de Paris. A história abarcada vai da metade do século XIX à atualidade. 
outra relação com o teatro do passado, uma visão concreta que só é poeirenta - acusação frequente feita à ideia de um museu de teatro - se deixarmos a poeira se acumular sobre as vitrines, sobre os cartazes, sobre os tecidos... É esta acessibilidade que permite tanto não esquecer - ser esquecido é o destino de hoje em dia de vários importantes artistas do teatro francês, se eles não trabalharam em cinema - e de dispor de um espaço para que o imaginário funcione, ao se friccionar a materiais ou obras que são ao mesmo tempo lacunares, históricos, por vezes científicos, e poéticos.

O museu é, sabe-se, um dispositivo que permite não somente conservar, mas pensar a obra de arte com o recuo no tempo, com a vizinhança com outras obras e com a proximidade do espaço. Assim, se as obras de teatro não são realmente pensadas pelo cinema na França é talvez porque esse museu não existe. A exposição citada acima sobre o Expressionismo no cinema alemão, de um sucesso quase absoluto, carecia contudo da referência a Gordon Craig, cujos projetos foram tão expostos na Alemanha nos anos 20. Ora, numerosos tesouros ligados à herança de Craig estão no Departamento de Artes do Espetáculo da Biblioteca Nacional da França, dos quais se puderam ver algumas peças somente na ocasião da exposição "A ação restrita" no Museu de Belas Artes de Nantes, em 2005.

A ausência de um Museu de Teatro na França, mesmo que existam alguns lugares especializados que exponham obras ${ }^{5}$, ou algumas exposições consagradas ao teatro ${ }^{6}$, não está ligada ao fato que considera, no fundo, e em geral, que o único "resto" válido de um espetáculo é o texto teatral da peça, na sua confiabilidade manuscrita ou impressa?

\section{O sonho de um "Museu muito especial"}

O Teatro Francês ${ }^{7}$ não é um teatro como os outros. Quando se traz um manuscrito, há os Bustos que nos olham (Alexandre Dumas Filho - citado por Jules Claretie, ver nota 5,

p. VIII)

\footnotetext{
5 Ver por exemplo o Museu das Artes Forains, ou o Museu da Marionete em Lyon, apesar de ter sido recentemente fechado.

${ }^{6}$ Houve algumas de muito sucesso como O jogo e a rąão, sobre Antoine Vitez em 1994 em Avignon (CNT/MEC/INA/Nathalie Léger), a exposição de André Acquart (2007) já citada, passando pela exposição, em 1996, sobre a Comédie-Française, sobre a qual se falará adiante. De outubro de 2006 a março de 2007, em Moulins-sur-Allier, no Museu Anne de Beaujeu, uma exposição intitulada Um teatro como cenário apresentou peças vindas de diferentes coleções francesas (Museu Carnavalet, de Compiègne, Museu de Belas Artes de Nantes, Comédie-Française, BNF)

${ }^{7}$ Provavelmente está se referindo à Comédie-Française. (N. da T.)
} 
Houve nas Exposições Universais de 1878 e de 1889 um pavilhão consagrado às artes da cena. Prefiguração de um futuro Museu de Teatro? Em 1897, no prefácio da obra de um dos grandes conservadores-arquivistas da Comédie-Française, Georges Monval, As coleções da Comédie-Française, catálogo histórico e comentado (1897), o administrador Jules Claretie sublinhava a importância das riquezas abrigadas pela Comédie-Française, que constituíam "uma galeria dramática". Mas ele lamentava, por outro lado, que esse Museu, por causa da exiguidade do espaço, não fosse organizado nem aberto ao público. Ele falava da "possibilidade de dotar de alguma forma a cidade de Paris de um novo museu, muito especial e particularmente atrativo". E detalhava:

O museu onde se encontrarão as riquezas enumeradas é claro dos mais importantes, mas ele poderia se tornar mais vasto ainda e mais rico. Bastaria ter mais espaço. Eu sempre desejei - e reivindiquei a quem de direito - o aumento desse Museu da Comédie-Française, que seria, eu suponho, aberto ao público e ofereceria, juntos, agrupados com método, tanto obras esparsas que escolheríamos entre aquelas que nós somos obrigados a pendurar aqui e ali pelos corredores, em salas estreitas onde trabalham os colaboradores da administração. Que se a Cour des Comptes, por exemplo, renascesse das ruínas, que maravilhoso local para pendurar essas telas, para esse museu de arte dramática. Repito que seria preciso aumentar o museu da Comédie-Française, e torná-lo acessível à multidão. Poderíamos então realizar uma classificação definitiva. (CLARETIE, 1897, pp. V-VII)

E descrevia como repartir as obras mais eficientemente nas salas.

Em 1905, outro prefácio do mesmo Jules Claretie, dessa vez para a obra de Emile Dacier, arquivista paleógrafo ligado à Comédie-Française, intitulava-se corajosamente dessa vez O Museu da Comédie-Française 1680-1905, (1905). Claretie voltava à carga para ressaltar que a demanda pela abertura desse "museu especial" vinha sendo feita desde $1886^{8}$. Ele descreve também o exílio dos bustos, salvos quando do incêndio do teatro: "no frio pavimento térreo do Louvre onde eles foram recolhidos, organizados durante a exposição de 1900. Apesar do bom gosto e os cuidados dos conservadores, esses mármores pareciam exilados" (CLARETIE, 1905, p. XI).

Claretie insiste argutamente sobre dois aspectos essenciais da questão: a necessidade de se abrir um Museu de Teatro porque os objetos produzidos em torno do espetáculo são numerosos e a de abrir esse museu a um público amplo próximo de um teatro em atividade, ou em seu seio, para lhe conferir um sentido.

Em 1942, Emile Fabre por seu lado conta, na sua História da Comédie-Française, as atribulações das coleções que comportavam então milhares de peças.

\footnotetext{
${ }^{8}$ Ele remete a um artigo de M.de Got na Gazette des Beaux-Arts.
} 
Levadas de aposento em aposento, manipuladas por mãos indiferentes ou pouco respeitosas e às vezes desonestas, misturadas de qualquer jeito em caixas ou sacos, guardadas em sótãos ou porões, não há porque se espantar que um grande número de arquivos tenham desaparecido, perdidos para sempre ou recolhidos por outras bibliotecas, por particulares, por bancas dos livreiros da beira do cais (FABRE, 1942, p. 148).

Ele descreve como o ator Régnier os "tirou de um longo sono" descobrindo ao longo de um minucioso trabalho de triagem e de classificação "o precioso registro de Lagrange" (Idem, p. 148), depois o modo como os arquivistas que o seguiram cuidaram de sua herança. "Mas, se interroga ele, esses arquivos, essa biblioteca, essas obras de arte, quadros, estátuas e bustos, amontoados na Comédie, não correm nenhum perigo?”

$\mathrm{Na}$ verdade, eles estão expostos a vários perigos. Em primeiro lugar, sendo o espaço limitado, os quadros estão encostados uns nos outros e, a não ser aqueles expostos no foyer, estão pendurados em corredores muito estreitos. Nos dias de "gerais" ou "estreias", quando o público se precipita para os bastidores para felicitar o autor e os intérpretes, as telas sofrem um duro ataque de cotovelos ou arranhões das bengalas ou dos guarda-chuvas, algumas são riscadas, até rasgadas. Para ganhar espaço e colocar alguns quadros fora do alcance dos espectadores, o administrador, durante o tricentenário de Molière, tinha disposto algumas telas sobre as largas paredes da grande escadaria. No entanto, comissões administrativas e anônimos consultados pareceram ter se sentido sufocados por essa iniciativa que "poderia fazer a Comédie parecer um Museu". Não se pode negar que esse tinha sido exatamente o pensamento que tinha norteado aquele arranjo. Os quadros foram então repostos nos corredores ou dentro dos depósitos. Eles estão lá até hoje. (Idem, p. 148).

Emile Fabre insiste sobre a continuidade das iniciativas dos administradores do Francês, clamando pela criação de um Museu da Comédie, onde "se abrigariam as obras de arte, os quadros de prêmios, as peças importantes do arquivo, o mobiliário, os figurinos usados pelos atores célebres e as maquetes de cenário”. Em 1920, o Estado tinha destinado à Comédie-Française os espaços contíguos da Cour des Comptes, que estava de mudança, mas "um capricho ministerial" os transferiu rapidamente para "doá-los ao serviço da cooperação intelectual". Constatando o desaparecimento desta instituição, Faber reclama a restituição dos locais e traça planos muito concretos de obras a serem executadas para que “o Museu não seja independente da Comédie e que os espectadores possam visitá-lo durante os intervalos" (Idem, p. 149).

Projeto desejado que permaneceu sem execução. Hoje, uma biblioteca que leva, como a da Ópera, o nome de Biblioteca-Museu da Comédie-Française, instalada no fundo do jardim do Palais Royal, é enriquecida a cada mês com novos materiais, classifica as coleções, acolhe na sua pequena sala de leitura os pesquisadores que agendam consulta, organiza 
exposições na França e pelo mundo. Se a biblioteca-museu da Ópera possui uma galeria de exposição permanente onde se podem ver as maquetes alinhadas contra as altas prateleiras de livros antigos e um espaço para as exposições temporárias, na biblioteca-museu da Comédie-Française "as coleções existem e são de uma riqueza incomparável, mas as salas de exposição permanente não existem.” (SURGERS, 1982, p. 67)

Contudo, diversas manifestações - em 1925 na Comédie-Française por ocasião da Exposição de Artes Decorativas; em 1962, nas 21 salas do castelo de Versailles; ou então no tricentenário da Comédie-Française na Biblioteca Nacional da França, no Centro George Pompidou9 - deram uma idéia do que poderia ser um Museu de Teatro, “oferecendo a ocasião de confrontar as obras aos intérpretes, autores e atores, os rostos aos textos, os projetos de maquetes às realizações cênicas, os artistas aos artistas", por meio da história da trupe e das gerações que se sucederam (Idem, p. 67). A de 1925 restituía os objetos das coleções não somente à história do Francês, mas também a do teatro de corte, do teatro jesuítico, do teatro italiano e do teatro de feira.

Mais recentemente, em 1994, quando a sala de espetáculo do Francês foi fechada para obras, uma grande exposição foi ali instalada, intitulada "A Comédie-Française por trás da cortina", cenografada por André Acquart como uma vasta cenografia "posta em abismo". Ela agrupava, no hall, na escada de honra e no foyer figurinos, acessórios, quadros, retratos, "relíquias", manuscritos, maquetes, desenhos e croquis, vídeos e música, e se abria aos ateliês técnicos. "O museu que não se pode visitar", segundo a expressão de Emile Dacier (que classificava os museus de Paris em três categorias cujas outras duas eram: os que se visitam e os que não se visitam) (DARCIER, 1905, p. 1), abria-se completamente para o grande público, tendo sido um sucesso completo. Cerca de 2 mil pessoas por dia. A questão posta no catálogo pelo administrador de então: "Para quando o famoso Museu de Teatro?", foi retomada pela crítica. "Já é tempo que o Estado pense em um dia criar um Museu de Teatro francês digno de sua história" (THIBAUDAT, 1994). Outras personalidades além dos administradores da Comédie-Française também pediram o Museu e, em particular, o ator e diretor Firmin Gémier, diretor da Sociedade Universal de Teatro, nos anos 20.

Pode-se ler nessa falta permanente a ausência de uma política teatral coerente que reflete também os problemas quanto à reflexão sobre a formação dos artistas, da cena e do público. Como se pode deixar de lado o teatro no momento da grande relookage sobre os

\footnotetext{
${ }^{9}$ Pode-se acrescentar a esta lista uma exposição itinerante organizada por Sylvie Chevalley, então bibliotecária da Comédie-Française, que viajou por diversos museus do interior em 1974-1976.

$10 \mathrm{O}$ curador da exposição foi Noëlle Guibert, encarregado então das coleções da Comédie-Française. O catálogo foi realizado por Noëlle Guibert e Jacqueline Razgonnikov.
} 
museus franceses? Por que não se propôs diante do entusiasmo dos visitantes franceses um grande Museu de Teatro? Devemos nos interrogar seriamente sobre isso.

\section{Conservar, formar, criar}

Sabe-se há muito tempo que a glória de um ator é só fumaça, que, depois de sua morte, dela nada resta e que sua memória desaparece. Por sua vontade e energia, o senhor realizou uma grande obra: tornou eterna a memória do ator. Se embora como pessoa isso não fosse necessário, necessitamos da lembrança dos ideais aos quais ele serviu. (Maria Ermolova11 a A. Bakhrouchine, 7 de dezembro de 1919).

Fora com os quadros na grande escadaria que teriam dado à Comédie-Française ares de museu! Esse episódio relatado por E. Fabre reflete uma raiva pela história que mal mascara a raiva pela criação. Um museu impediria criar novidades? Não se pinta mais por que existem museus? Grandes artistas que abriram ao futuro o teatro pensaram sobre um museu. Assim, o museu parecia a Gordon Craig como uma das ferramentas de trabalho da escola de teatro que ele fundou na Arena de Goldoni em Florença em 1913. Ele queria expor sua própria coleção, lentamente constituída de livros preciosos, documentos, objetos raros: máscaras e marionetes vindas do Oriente - Índia, Java, Japão, Birmânia - ou da África. A escola durou apenas um ano por causa da guerra que acabou com a experiência. Contudo, os alunos-assistentes de Craig encontraram tempo para "construir vitrines para o museu do qual se fez um inventário das riquezas.” (BABLET, 1962, p. 53)

Para Vsevolod Meyerhold, o funcionamento de seu teatro deve ser acompanhado de um museu onde os espectadores, nos intervalos, pudessem examinar as diferentes etapas de criação da trupe, o itinerário da pesquisa dos anos 20 e 30: os espetáculos que precederam aqueles que estão em sendo assistidos, ou os processos de trabalho da obra em questão. Quanto a Constantin Stanislavski, ele invoca desde 1907-1908 o respeito aos arquivos, se preocupando vivamente e nomeando como crime imperdoável a negligência com a qual o seu teatro os trata:

É difícil, escreve ele, ligar esses dois polos: de um lado, a alta cultura do nosso teatro, de outro, a incompreensão bárbara do valor artístico dos materiais que possuímos, dos troféus, dos documentos da encenação. (...) Um museu e uma biblioteca saberiam considerar essas coisas com interesse e orgulho. Isso seria vantajoso não somente para os espetáculos futuros, mas também para a escola, preocupada em estudar todas as épocas" (STANISLAVSKI, 1997, p. 53).

\footnotetext{
${ }^{11}$ Grande atriz russa.
} 
"Ele constata que nosso teatro não é suficientemente grande para se dar conta da importância de um museu, de uma biblioteca ou de arquivos artísticos” (Idem, p. 53) ${ }^{12}$. Mais tarde, Giorgio Strehler pensará também, no Piccolo Teatro de Milão, em um trio eficiente: teatro, escola e museu.

Para saber para onde se vai, é preciso compreender de onde se veio. Esse adágio é tão mais necessário pois, efêmero, o espetáculo se inscreve assim mesmo na história de uma arte à qual os artista devem ter consciência de pertencer. Os mais revoltados, os mais inovadores, foram e são com frequência aqueles que a conhecem melhor. Pois o Museu permite não voltar a (prática vaga e nostálgica), mas recomeçar de (prática refundadora).

Contra tudo, o perecível da cena resiste. Resiste aos próprios artistas, que às vezes não percebem o valor desses "restos" e os relegam negligentemente a uma mala sob suas camas, como fazia Roger Blin; resiste às atribulações das heranças e vendas em leilões, de uma coleção particular à outra, ou aos arquivos públicos. Resiste, às vezes, aos incêndios. E mesmo à repressão política.

A história da cenografia e do figurino do suntuoso Bal Masqué (de Lermontov) dirigido por Meyerhold em 1917 (seis anos de pesquisa com o cenógrafo Alexandre Golvine, centena de rascunhos e maquetes), retrabalhado em 1933 e 1938, logo proibido depois do assassinato do diretor em 1940, é, a esse respeito pelo menos, animador. Divulgou-se que durante a guerra uma bomba havia destruído o depósito onde todos os "restos" do Bal Masqué tinham sido colocados. Ora, percebe-se que se tratou de um ruído que um misterioso "alguém" espalhou para proteger os tesouros malditos: há alguns anos quase todos os cenários, cortinas, figurinos foram encontrados intactos na reserva do Teatro Alexandrinski de São Petersburgo onde foi criado o Bal Masqué. Cerca de cinquenta figurinos (de cento e sessenta - pertencentes à encenação original ou às reprises-variantes) estão hoje expostos em um dos foyers desse teatro, na "Sala Golovine", nome do cenógrafo desse lendário espetáculo, com outros elementos da cenografia: biombos, mobiliário, acessórios - e rascunhos. O Teatro Alexandrinski dotou-se recentemente de um Museu no seu interior. Graças a reformas e à transferência de toda a parte administrativa para um imóvel vizinho, todo um andar pode ser recuperado e dedicado à história. Oito salas foram abertas, onde os espectadores podem ver desenrolar-se séculos de teatro: a "sala dos boiardos" com as encenações do século XVI, uma sala consagrada ao século XVIII, outra, batizada a partir de uma obra de Gogol, $A$ saída do teatro, é centrada sobre a representação teatral da vida russa do século XIX. A "sala Hamlet" é consagrada a

\footnotetext{
${ }^{12}$ Constantin Stanislavski. Notes artistiques. Circe/TNS, 1997, p.53.
} 
diferentes interpretações da peça, de Karatyguine a Kozintsev. Seguem-se uma sala Tourgueniev, que expõe as pesquisas da atriz Savina, a primeira a interpretar Tourgueniev, uma sala Gogol, uma "sala imperial”, e a famosa "sala Golovine”... É interessante notar que a ideia desse museu veio a Alexandre Chepourov, teatrólogo que o organizou, quando de uma visita a Paris, diante da cadeira de Molière exposta na Comédie-Française!

Se o Teatro Alexandrinski reivindica hoje sua ligação com o passado, ele não procura de jeito algum permanecer sob seu domínio. Em São Petersburgo, na praça Puchkin, teatro, museu de teatro (1999, p. 71 sqq) e biblioteca teatral são próximos e formam um conjunto na vida cultural da cidade. Em maio de 2007, o Museu do Teatro de São Petersburgo apresentou uma exposição sobre o Teatro Alexandrinski que destacava outros figurinos do Bal Masqué.

Em Moscou, o Museu do Teatro leva o nome de seu fundador, A. Bakhrouchine, que o inaugurou em 1894 a partir de suas coleções, progressivamente organizadas a fim de cobrir a história do teatro russo e o transferiu, em 1913, para a Academia de Ciências. Esse museu foi incluído em 1918 na rede de estabelecimentos nacionais. Constantemente enriquecido, equipado com uma biblioteca, ele funciona hoje com poucos recursos, mas organiza, em Moscou e no exterior, exposições temporárias que recortam as coleções permanentes: seu diapasão se estende portanto de Gonzaguo a Fomenko. O princípio do Museu de Teatro foi assim encorajado pela política pós-revolucionária, mas seu embrião é fruto de uma iniciativa privada. Em 2007, o Museu Bakhrouchine expôs os desenhos de Golvine (cortinas, dispositivos, figurinos e mobiliário) para o Bal Masqué, uma vez que foi ele que soube adquirir esses tesouros. Resta aguardar que as instituições das duas cidades possam um dia superar os problemas de segurança para apresentar em conjunto desenhos e objetos... Duas outras exposições, uma sobre Chaliapine, outra sobre os Balés Russos, desenham o vasto campo de interesse de um museu que não separa teatro dramático, ópera e dança.

Ao lado do Museu Bakhrouchine (cujo logotipo o apresenta como central), existem numerosos museus de teatro em Moscou. Dentre eles, o Museu do Teatro de Arte, fundado em 1923, expõe uma parte de seus fundos de arquivos que concernem à história desse teatro e reúne também coleções pessoais de Stanislavski, Nemirovitch-Dantchenko, e outros grandes nomes daquele teatro. Concebido com a mesma arquitetura interna que o Teatro, é como seu prolongamento natural. Encontra-se aí, por exemplo, uma das minúsculas maquetes concebidas por Craig para Hamlet. Há também a Casa-museu de Stanislavski; o apartamento-museu de Nemirovitch-Dantchenko; o apartamento-museu de 
Maria Ermolova; o museu do Teatro Musical Stanislavski e Nemirovitch-Dantchenko, recentemente reformado em prol da reabilitação desse teatro; e o apartamento-museu de Meyerhold, filial do Museu Bakhrouchine, que só foi aberto depois de inúmeras e penosas articulações e lutas, onde há lugar para as exposições temáticas... Hoje, um Museu Borovski, dedicado à obra do grande cenógrafo está em discussão.

Encontram-se museus de teatro, generalistas ou centrados sobre uma personalidade em particular em todos os países da ex-Europa do Leste - República Tcheca, Hungria, Polônia, - mas também em Amsterdã, Lisboa, Estocolmo, Viena, Melbourne, Londres. Seu funcionamento e sobrevivência não são simples dentro do contexto econômico e cultural. Em Londres, por exemplo, o Museu Nacional das Artes do Espetáculo, fundado em 1924, dependente do Museu Victoria e Albert, acaba de fechar suas portas por pressão de sua direção, que deseja retomar seu espaço ${ }^{13}$. Uma mobilização internacional de protesto não conseguiu reverter a decisão tomada em 7 de janeiro de 2007.

\section{Um desafio, um projeto real?}

$\mathrm{Na}$ presente configuração, na qual os museus de teatro que existem podem fechar, pode-se pensar que evocar novamente essa "velha serpente marinha" que é o Museu-deTeatro-na-França não passa de uma elucubração quixotesca... mas, o sonho ainda existe, entre os pesquisadores, conservadores, artistas e até entre os colecionadores privados. E é tocante ler em um catálogo da dispersão recente da coleção de Jacques Lorcey que ele pensava estar reunindo "o embrião desse Museu do Espetáculo”.

Pois esse pode ser um verdadeiro projeto a ser colocado no centro de uma política para o teatro; um projeto pioneiro em muitos aspectos: conservação-exposição-formaçãocriação. Criar um Museu do Teatro significaria que se reconhece inteiramente a importância da história dessa arte para os artistas e que portanto seu ensino (nos Institutos de Teatro da ex-Europa do Leste, os alunos têm, todo ano dos 4 ou 5 anos do seu curso, aulas dessa disciplina), seria facilitado por meio dessa abertura. Bem pensado, ele favoreceria uma renovação durável da criação. É o diretor Jean-Pierre Vincent que confessa:

Penso que (...) aqueles que ignoram o passado estão condenados a revivê-lo; isto é, crer que está fazendo algo novo quando fazem coisas que já foram feitas há 20, 30, ou 50 anos. O teatro francês, no seu individualismo, não é como o teatro alemão nem como o teatro russo, alimentados pela história e pela memória. É como se cada geração quisesse fazer tábula rasa. E essa é nossa fraqueza" (1999, p. 97).

\footnotetext{
${ }^{13}$ Foi possível acompanhar ativamente os acontecimentos no site www.theatremuseumguardians.org.uk.
} 
Um museu do teatro... sonhemos portanto com algo que ainda não existe em lugar nenhum. O qual deveria, sem dúvida, para que as salas de exposições fossem revitalizadas por um contexto animado e dinâmico, estar situado na proximidade de um local dedicado à prática - uma escola, instituto de pesquisa, teatro ou cidade do teatro se se quiser ser ambicioso e duradouro. Esse museu, para agrupar as riquezas vindas de diversos lugares de arquivamento, não precisaria se espalhar em espaços desmesurados porque ele faria uso das novas tecnologias e funcionaria em rede com outras coleções. Os objetos expostos teriam toda a concretude e magia do passado real, o virtual permitiria invocar os fantasmas que povoam os tablados. Seria necessário confiar a complexa apresentação aos cenógrafosinformáticos que amam e conhecem a história de sua arte. Seria preciso interessar-se pelos trabalhos de um laboratório como o LAMIC em Quebec (Universidade Laval) que conduz pesquisas sobre novas tecnologias museológicas. Aí são testados aparelhos utilizando tecnologia muito avançada - um panoscópio, pavilhão para desenvolver ambientes de imersão, um ciclorama em 3D. Pode-se imaginar como tais pesquisas poderiam nutrir o projeto de um Museu de Teatro "diferente" ou as criações contemporâneas.

O lugar deverá ser imaginado de tal maneira que as grandes tradições e grandes revoluções possam ser compreendidas e apreciadas, sempre guardando seu mistério e seu estranhamento. Eu me lembro de uma exposição de maquinismo teatral do século XVIII em um anexo do Museu Pushkin em Moscou - máquina de chuva, de vento, de tempestade que os visitantes manipulavam diante de um pequeno palco onde eles podiam imaginar esta ou aquela peça realizada - e do efeito produzido por essas máquinas de madeira, ao mesmo tempo, rústicas e sofisticadas. Ele deveria também mostrar a relação com outras artes do espetáculo - dança, musical, cinema - às quais o teatro sempre esteve ligado.

É preciso, como se viu, que um tal museu confronte o espectador à materialidade texturas, cores, concretude, bricolagem, técnicas... -, e à poesia desses materiais de arquivo que se encaminham a desaparecer progressivamente, já que tantos documentos hoje, a começar pelos escritos, são digitais. Contudo, ele deverá saber prever difundir documentos em vídeo ou fílmicos em telas planas que se pode hoje pregar nas paredes ou pendurar no vazio e utilizar o virtual para comentar os documentos reais, contextualizá-los ou fazer desfilar outros objetos da mesma natureza pertencentes a outros lugares ou coleções, já que será evidentemente impossível mostrar tudo. As salas de exposição permanente, compostas por objetos escolhidos, seriam vivificadas por exposições temporárias sobre temas específicos, sobre a atualidade do espetáculo, sobre alguma coleção em particular, ou sobre o balanço da cenografia de uma temporada. Há dezenas de anos, existe na Rússia uma 
exposição anual chamada "balanço da temporada" quando se expõem as melhores cenografias desse imenso país, o que ajuda os cenógrafos, jovens e menos jovens, a tomar consciência do nível geral da sua profissão e a se desenvolver ${ }^{14}$. As exposições temporárias poderiam também encontrar abrigo na Internet.

Uma verdadeira política de teatro não passa somente por decisões racionais - e não caprichosas - quanto às nomeações das direções dos teatros e dos centros dramáticos franceses; ela passa também por esse gesto de envergadura capaz de mobilizar o conjunto de energias e de financiamentos no grande público e no setor privado. É tarde, claro, mas uma criação tardia no século XXI implicaria numa ação que leva em conta a experiência dos museus existentes (como o pequeno Museu do Teatro em Epidauro que projeta os visitantes nas imagens e nos sons), novos modos de exibição, o estado avançado das tecnologias e que eleva a instituição assim imaginada a um nivel e a uma finalidade europeias. Pode-se pensar também que assim se criariam, por intermédio de equipes especializadas, os DVDs inventivos a partir dos tesouros escondidos nas fontes múltiplas, privadas ou institucionais que cederiam seus direitos, hoje geralmente exorbitantes, para objetos pedagógicos e culturais.

Em 1922, um cineasta chamado René Jeanne pedia, suplicava, a criação de um "museu dos gestos dramáticos" que utilizaria "a potência e os recursos do cinema" para "libertar todos os artistas da posteridade dos vícios" (JEANNE, 1999, pp. 17-21). Um museu do teatro dedicado à inovação na conservação e ao serviço da criação seria sem dúvida melhor do que se faz atualmente para resolver os problemas postos aos "filmes de teatro" ${ }^{15}$; ele poderia realizar o sonho desse visionário, reunir as cópias de transmissão, gravações de áudio e audiovisuais conservados tanto na BNF como na INA, cuidar dos filmes e dos documentos que vierem a ser produzidos. Ele teria como objetivo agrupar a memória estilhaçada do teatro francês, pois não é bom, para seus artistas e seu público, que esses fragmentos permaneçam isolados. E transmitir, para fecundar o presente, sua história original - na sua continuidade e rupturas, nas suas pequenas e grandes formas, nas suas teorias e anedotas, no seu brilho e nos seus eclipses -, uma história que faz parte da história européia do teatro, por essência, viajante.

\footnotetext{
${ }^{14}$ Um catálogo é editado nessas ocasiões.

${ }^{15}$ Comédie-Française. Le film de théâtre, sob a direção de B.Picon-Vallin, Paris, CNRS Ed., 1997.
} 
Les cabiers de la Comédie-Française. no30, 1999.

BABLET, Denis. E.G. Craig. Paris, L'Arche, 1962.

CLARETIE, Jules, Preface. In: MONVAL, Georges, Les collections de la Comédie-Française, catalogue historique et raisoné. Paris, Société de propagation des livres d'art, 1897.

Preface. In: DACIER, Emile. Le musée de la Comédie-Française 1680-1905. Paris,

Librairie de l'art ancien et moderne, 1905.

DACIER, Emile. Le musée de la Comédie-Française 1680-1905. Paris, Librairie de l'art ancien et moderne, 1905.

FABRE, Emile. La Comèdie-Française: Histoire d'une societé de comédiens à traveres les siècles. Paris, Nouvelle Revue Critique, 1942.

JEANNE, René. Un musée de gestes dramatiques. In: Noëlle Guibert. Les cabiers de la ComédieFrançaise, nº30, 1999. pp.17-21.

STANISLAVSKI, Constantin. Notes artistiques. Circe/TNS, 1997.

SURGERS, Anne. La Comédie-Française: Un théâtre au-dessus de tout soupçon. Paris, Hachette, 1982.

THIBAUDAT, Jean-Pierre. La garde-robe de la Comédie-Française. In : Libération, 15/10/1994.

Résumé: Cet article présente l'idée de la création d'un Musée de Théâtre en France. Pour cela, il trace une vue retrospective sur ce sujet en France et sur existence d'autres musées dans le monde, surtout em Russie.

Mots-clefs: Musée du Théâtre ; histoire du théâtre ; Comédie-Française ; France ; Russie. 